\title{
Introduction \\ Material Agency as a Challenge to Empirical Research
}

\author{
Stefan Böschen, Jochen Gläser, \\ Martin Meister, and Cornelius Schubert
}

Recent years have seen an increasing interest in materiality in social research. Some might say that materiality is now back on the agenda of social research. The challenges of bringing materiality back have spurred lively debates about material agency, most of which, however, are leveled at the largely dematerialized theories of the social in the social sciences, for example, in material culture studies (Appadurai 1986; Miller 1998) as well as science and technology studies (Latour 1988; Law/Mol 1995). Since the turn of the century, a marked shift towards the material has emerged (cf. Hicks 2010), ranging from questions concerning nature (Grundmann/Stehr 2000) and everyday objects (Molotch 2003; Costall/Dreier 2006; Miller 2010) to issues of cultural theory (Reckwitz 2002), post-phenomenology (Verbeek 2005), ethnography (Henare et al. 2007), distributed cognition (Hutchins 1995), and materiality in general (Dant 2005; Miller 2005; Knappett/Malafouris 2008). A perspective on materiality is now being developed in diverse fields such as archaeology (Meskell 2005), economic sociology (Pinch/Swedberg 2008), political science (Bennett 2010; Coole/ Frost 2010), and organization studies (Carlile et al. 2013). Yet the status of the material remains debated in the evolving fields of various "new" materialisms (cf. Lemke 2015)

More often than not, the arguments center on how to tackle material agency conceptually, that is by assigning agential qualities to things; yet there are very few efforts to engage with material agency on the methodological level. This special issue was conceived out of an understanding that addressing conceptual questions before methodological ones is taking the second step before the first. What might be even worse is that by addressing material agency in a conceptual way, the "material" of material agency itself disappears behind abstract concepts. It seems an odd feature of materiality that it becomes an elusive and fugitive matter when getting in touch with theory (Button 1993). ${ }^{1}$ This special issue is motivated by the question of why ma- 
teriality is so difficult to deal with, not just conceptually, but more importantly in terms of research methods. Is it because our methods intrinsically strip social phenomena from their material substrate? Do they implicitly or explicitly favor cultural aspects of social life over material ones? Or do social scientists simply lack the knowledge to adequately deal with material agencies?

Because these questions will be answered differently depending on the field and phenomena under study, we do not seek grand, abstract, and unspecific concepts, but rather look for specific approaches that reflect the diverse interrelations between material agency and social phenomena in various fields of social life. Instead of looking for final answers to the challenges material agency poses to empirical research, we are interested in identifying the ways in which specific research problems with material agency arise and how they are met by research designs in different fields. For the introductory purpose of this editorial, we will revisit some of the conceptual arguments concerning material agency and relate them to the methodological issues they entail. While referring to the recent discussions on material agency, we hope to find some fruitful lines of thought that may serve as a guide through the contributions in this issue.

\section{The Methodological Blind Spot of Grand Theories about Material Agency}

The flourishing theoretical debate on materiality in recent years has been fuelled by many fields. Among others, technology, science, gender, political, and organization studies have engaged in bringing materiality back in. Generally, the arguments are right to point out that theories of the social have been unjustly cleansed of materiality and they have attempted to reinstate materiality's analytical status. This has been a central concern of Actor-Network Theory for nearly three decades (Sayes 2014). But also post-structuralism, post-phenomenology, research on distributed cognition, and feminist and practice theory have provided relevant insights into the relevance of materiality for understanding social phenomena.

However, these approaches do not tell us which methods to use or how to proceed in order to empirically study material agency. Instead, theory is illustrated by fitting examples and illustrations that an average reader can understand. In fields like science studies, however, we either need a great deal of knowledge in order to understand the 
empirical details or we have to trust the scientists and authors that the material world actually behaves in the described way. This tension can be seen at work in the so-called chicken debate (Callon and Latour 1992; Collins and Yearley 1992) —albeit only on a very abstract epistemological and conceptual level.

This brings us to the central question pursued in this special issue. We can make out a broad range of conceptual approaches to material agency, which have been fruitfully exploited over the last decades. But how do we deal with material agency in empirical research? The easiest way is to funnel it through the accounts of the actors. Only what is deemed socially relevant in actions, interviews, and societal discourse will be used in the analysis. This way, we are trying to come to grips with materiality through the domain of the social. We look at what people do with things, how they talk about them, how things are being exchanged or evaluated. Metaphorically speaking, we are picking up some resonances of materiality as they are transmitted through the medium of the social —we look at things in terms of the meanings humans attach to them. This is by far the most common way to proceed and there are good reasons to do so. However, this approach has a serious limitation. Material agency unfolds not only indirectly through actors' construction of it but also quite directly (and sometimes brutally). Our success in crossing a frozen lake depends not only on our assumption that the ice will be thick enough (which makes us start across) but also on the actual thickness of the ice (which contributes to our successful arrival). Thus, social constructions and material agency may "disagree", and these disagreements affect the social phenomena we want to investigate. This is why we would like to push the methodological discussion a little further. We first ask about the variations of materiality by sketching a range of aspects in which it manifests, and subsequently discuss the variation of influences these aspects can have on human action in terms of material agency.

\section{Variations of Materiality and Material Agency}

Depending on the discipline and field of study, different things or different kinds of materiality come into focus. First, we can draw the classic distinction between naturally occurring objects and humanmade artifacts. While naturally occurring objects indicate only marginal human involvement (if at all), artifacts by name are human creations. Of course, this dichotomy is hard to maintain in the face of 
ongoing human involvement with nature. It could even be argued that any involvement by humans with naturally occurring objects instantly makes them a part of cultural processes. But this is not the right place to elaborate on different object classifications. For our purposes, it is sufficient to note that we start with the simplest notion of materiality as things that have a material substance. A thing might be anything as long as it has a materiality. Artifacts, in turn, are things created by humans. They might be pieces of art or instrumental devices. And of course, many of the instrumental devices, the tools, are oriented toward some form of natural materiality.

As we said, things are perceived differently by different disciplines. In science studies, for instance, Rheinberger's (1997) distinction between "epistemic things" and "technical objects" connotes the epistemic status of things, depending on whether they are still unknown or well-understood. In technology studies, Latour (2002) distinguishes between mediators and intermediaries, the former resisting or transforming human action or intention, the latter working as expected. The design of many modern everyday things can also be analyzed in cognitive terms (Norman 2002 [1988]), as they sometimes baffle the user trying to understand how to operate them. Ethnology and archaeology are usually oriented toward low-tech artifacts, whereas science and technology studies often deal with hi-tech environments. Architecture is concerned with large creations, whereas in many sciences the objects of interest are rather small. The point is that when we deal with materiality, we often deal with things that embody different aspects of materiality-soft or hard, big or small, heavy or light. However, although materiality comes into play through different facets, we are not interested in any isolated features of materiality but in their interrelations with social conduct. Material things then do not often appear clear-cut or easy to identify, but are instead composed as mixtures of meaning and materiality.

Many approaches to materiality conceive it as an opposing force to human action. In science studies, Pickering made this concept of material agency prominent as the "mangle of practice" (1993). Such material agency does not exist by itself, but only in its entanglement with human agency. His example of scientific experiments in particle physics traces a long historical process of mutually adapting scientific instruments and theories. If the scientific experiment fails to yield the expected results, scientists are forced to adapt their experimental setup. Pickering is careful not to reduce material agency to isolated material effects and conceptualizes it in close connection with hu- 
man agency. However, at the end of his story (especially in Pickering 1995), we find a dialectic of resistance and accommodation that quite brutally abstracts from the rich and detailed account of years of scientific experimentation. In the end, material agency is mainly located in resistance to human intention.

We can take up three interesting questions from this short recapitulation. First, does material agency really only play a role as a form of resistance to human action? Second, is material agency always passive in relation to the activities of humans? Third, can material agency be analyzed in isolation from human action? The first and second aspects entail some distinct notions of material agency that should be spelled out a little more. Conceiving material agency mainly as resistance shuts out the affordances of materiality, the way objects might guide, channel, or force actions (Gibson 1986 [1979]). It also neglects the capacity of instruments and physical structures to organize individual memory and collective actions, and to simplify choice and perception, as is broadly described in studies about distributed cognition (Hutchins 1995; de Léon 2006). In a similar vein, it ignores the materiality of decay and the constant need for repair and maintenance (Harper 1987; Orr 1996). It also neglects other forms of engagement with objects, which are not predominantly instrumental_-for instance, the emotional and sensual side of engaging with material artifacts in everyday life (Miller 2008) as well as in science (Turkle 2008).

If we think of material agency mainly as a passive force, this forecloses processes in which it actively initiates specific human actions. Because things decay, rot, and rust, they require constant maintenance in order to serve the purposes we assign to them. We also take care of things we value. Other material processes might need constant attention to keep them going, like the controlled decay of radioactive materials in atomic power plants or the cultivation of bacterial specimens in biology. The material agency of these processes may be conceptualized in their resistance to being sped up, slowed down, halted altogether, or even reversed, but nevertheless these processes occur in a more active manner than the simple resistance of a rock lying in the way. These processes happen, in a way, in their own time. Of course, the entanglement of material and human agencies becomes more complex if we think of material agency as more active than passive. Last but not least, and probably the most interesting point from a methodological perspective, is the firm grounding of material in relation to human agency. While natural sciences are preoccupied with isolating pure material agency, social scientists look for the interrelations of 
human and material agencies, for example, in natural sciences. Therefore, the invocation to address the empirical challenges of material agency should not be misunderstood as a simplified Husserlian call "to the things themselves", but as a call to question how our empirical methods can actually deal with the entanglements of human and material agencies.

\section{Empirical Challenges of Materiality, Agency, and Meaning}

As we have noted above, material agency is mostly observed through the lens of the social. Methods such as interviews aim to produce text and thus accounts of materiality, but they do not give direct access to materiality in the objectified sense of natural sciences. Observations and especially participant observations may give hints to material agencies, but as we have already noted, there is no way to get to something like a "pure" material agency. The challenge thus resides in looking for methods that do not produce results biased either toward meaning or toward materiality, but that make it possible to better understand their mutual interrelation. Archaeology might be a good case in point here. Whenever potsherds are discovered next to traces of fire and indicators of settlement, these artifacts must be set in relation to each other and need to be stepwise put into the context of human action. On the one hand, artifacts that outlasted the systems of meaning around them and that are now reduced to their sheer materiality are carefully given meaning again. On the other hand, the everyday artifacts of today's industrialized societies are so heavily laden with meaning that it is difficult to make out their material agency. Balancing meaning and materiality thus seems to be an important issuehowever, we do not claim to have a simple solution at hand.

Against this background, the articles collected in this Special Symposium aim to meet these challenges in their application of specific disciplinary perspectives to the analysis of material objects. We have organized the contributions into two sets, each consisting of three articles. The first set follows methodical and methodological considerations, the latter is more concerned with concrete material objects.

In his article, Peter Stockhammer raises the question of how to characterize archaeological sources, bearing in mind the different foci of inquiry with regard to the archaeological analysis of an object, that is, its materiality, archaeological context, spatial distribution, and meanings and power. By proposing to integrate aspects of Actor-Net- 
work Theory (ANT), he differentiates between practices with things and of actions by things in order to describe the entanglement of human and non-human actors in shared networks. Moreover, he focuses on the aspect that in ANT time is not sufficiently taken into consideration and draws the conclusion: The "twofold Wandelbarkeit of an object-the permanent change of its perception and its change due to the transformation of its substances with time-needs to be taken as a basic insight" (Stockhammer, this volume, p. 280).

Tanja Cartensen provides an empirical investigation on how the internet as a technological and material object is shaping human work practices. Adding methods of usability and market research (which can get "closer" to the technological side of practice) to the common approaches of sociological internet research, she describes methods of observation and data collection: software-based recording and analysis of the interactions between humans and the internet that are visible on the screen. Based on these materials and her empirical findings, she proposes a typology of human-internet interactions, scaling the influence of technical materiality from total internet constraints to complete freedom of use and customization, with several distinguishable types between these more classic poles.

Focusing on the problem of comparing individual case studies, a problem notorious within the sociology of science, Grit Laudel and Jochen Gläser develop a methodological approach for the inclusion of things into the sociology of science. They start by distinguishing three fundamental methodological challenges: the necessity to use scientists' accounts of scientific things, the dilemma between depth and breadth of sociological descriptions, and the necessity to systematically relate accounts of scientific things to one another and to specific social conditions of research. Their own proposal starts from sociological theory of action and conceptualizes the materiality of things as an epistemic condition for any research action, quite equally (in a Latourian sense: symmetrically) to social structures. The fruitfulness of the approach is illustrated with empirical results from two comparative studies.

The contribution of Annina Schneller is driven by a concrete design problem that can be related to the agency of materials and things. The design rhetoric comes into place through the idea that "every design artifact is created with an intention to create specific visual (haptic, olfactory, and other) effects, and that this can be achieved by choosing appropriate formal or stylistic means" (Schneller, this volume, p. 339). Not the explanation why, but the knowledge of how specific stylistic 
means create specific effects is important for this approach. Consequently, the agency of things is related to specific design rules. They allow a designer to design things in a way that allocates them to a defined agency. Nevertheless, the agency of things becomes manifest in terms of the non-intended side-effects of design rhetoric.

In her article, Anna Henkel uses a study of the development of pharmaceutics in Germany for a demonstration of two ways in which actor-independent accounts of things can be constructed. Both approaches are inspired by major constructivist frameworks. Inspired by Latour, Henkel constructs a symmetrized view on drugs by juxtaposing the definitions of drugs used by main groups of actors for whom drugs are matters of concern. The second approach is inspired by Luhmann and the tradition of semantic analysis. It treats things as identity structures and reconstructs the change of main expectations and dominant classification schemes over time. The combination of both perspectives offers two analytical opportunities: to deeply analyze the struggle for the meaning of things on the one hand and to observe a "shifting material basis of things" (Henkel, this volume, p. 378) on the other.

Torsten Cress' observations of Catholic liturgy make use of ethnographic methods in order to account for the materiality of the Holy Mass. He seeks to reveal the involvement of objects in social situations in light of Goffman's frame analysis and sociological practice theories and argues for a stronger engagement with "object-oriented ethnography." The rituals of Catholic liturgy can then be analyzed as bodily encounters with sticky oils, drops of wine, crumbling pieces of bread, and lengths of cleaning cloth. The analysis shows how these objects are not mere decorations or props for staging the rituals, but that their materiality may also interfere with or resist their smooth integration into the procedures. It also shows that meanings and materiality can hardly be separated and how cultural or material reductionisms fail in the light of empirical research.

As a whole, the contributions illustrate the variety of research problems in the social sciences to which material agency matters, as well as the many methodological challenges included in the empirical investigation of things. The methodological challenges reach from very concrete problems of data collection and interpretation to more fundamental methodological and even epistemological choices. On more concrete levels, the question is how data about things (and human interaction with things) can be collected and analyzed. On the more abstract level, questions must be answered about possible forms 
of agency and relevant material properties on which data must be collected, about the role of meanings assigned to things by ourselves and those we study, and about ways in which "objective" information on things can be derived from accounts of those we study. It is obvious that on all these levels, the different disciplines engaged in studying things can learn from each other. With this Special Symposium, we hope to promote such learning.

Stefan Böschen is senior research scientist at the Institute for Technology Assessment and Systems Analysis (ITAS) at KIT (Karlsruhe Institute of Technology). He studied chemical engineering, philosophy, and sociology and earned a doctoral degree in sociology with a "habilitation" in sociology. His current focus of research is on sociology of science, technology assessment, and analysis of risk politics. He is Principal Investigator for the projects "Regional Climates," funded by BMBF (2010-2014), and "Resilience through Experimental Institutionalization," funded by Bavarian StWKF (2013-2017). Recent publications include: Safia Azzouni, Carsten Reinhardt, and Stefan Böschen, eds. 2015. Erzählung und Geltung: Wissenschaft zwischen Autorschaft und Autorität. Weilerswist: Velbrück. Address: ITAS / KIT, Karlstr. 11, 76133 Karlsruhe, Germany. E-mail: stefan.boeschen@kit.edu.

Jochen Gläser is a senior researcher at the TU Berlin's Center for Technology and Society. He is a sociologist of science whose major research interest is the interaction of epistemic and institutional factors in the shaping of conduct and content of research at the microlevel of individuals and groups as well as the mesolevel of scientific communities. Other research interests include organizational sociology, bibliometrics, and qualitative methods. A recent publication is Richard Whitley and Jochen Gläser, eds. 2014. Organisational Transformation and Scientific Change. Bingley, UK: Emerald Group Publishing Ltd. Address: Zentrum Technik und Gesellschaft, TU Berlin, Hardenbergstr. 16-18, 10623 Berlin, Germany. E-mail: jochen.glaser@ ztg.tu-berlin.de.

Martin Meister is a research and teaching associate at the University of Duisburg-Essen. His main research interests are the sociology of technology and science and technology studies, and more generally sociological theory. His actual focus is on Ubiquitous Computing and Robotics. He holds a master's degree in political science and a doctoral degree in sociology. His most recent publication is: Martin Meister. 2014. "When is a Robot Really Social? An Outline of the Robot Sociologicus." Sti-Studies 10(1): 85-106. Address: Universität Duisburg-Essen, Institut für Soziologie, Lotharstr. 65, 47057 Duisburg, Germany. E-mail: martin.meister@uni-due.de.

Cornelius Schubert is a postdoc researcher in the DFG research training program "Locating Media" at the University of Siegen. He specializes in sci- 
ence and technology studies, medical and organizational sociology, and innovation studies. His interests lie in micro-analytical studies of technologies-in-use and the unfolding of technological paths. He holds a master's degree in sociology, psychology, and linguistics as well as a doctoral degree in sociology. Recent publications: Cornelius Schubert. 2013. "Distributed Sleeping and Breathing: On the Agency of Means in Medical Work." In Agency Without Actors? New Approaches to Collective Action, ed. JanHendrik Passoth, Birgit Peuker, and Michael Schillmeier. Address: DFGGraduiertenkolleg Locating Media, Universität Siegen, Am Eichenhang 50, 57076 Siegen, Germany. E-mail: cornelius.schubert@uni-siegen.de.

\section{Notes}

1. This "de-materialization" is rooted in the history of many theories of technology. In sociological as well as philosophical approaches, materiality has tended to evaporate from concepts of technology, such as in Ellul's (1964 [1954]) concern with "technique" as method and not as materiality: "Technique has now become almost completely independent of the machine, which has lagged far behind its offspring" (Ibid.: 4). Similarly, Heidegger's (1977 [1962]) notion of "enframing" loses all technical and material aspects: "Enframing means that way of revealing which holds sway in the essence of modern technology and which is itself nothing technological" (Ibid.: 20).

\section{References}

Appadurai, Arjun, ed. 1986. The Social Life of Things: Commodities in Cultural Perspective. Cambridge: Cambridge University Press.

Bennett, Jane. 2010. Vibrant Matter. A Political Ecology of Things. Durham: Duke University Press.

Button, Graham. 1993. "The Curious Case of the Vanishing Technology." In Technology in Working Order: Studies of Work, Interaction, and Technology, ed. Graham Button, pp. 10-28. New York: Routledge.

Callon, Michel, and Bruno Latour. 1992. "Do Not Throw Out the Baby with the Bath School." In Science as Practice and Culture, ed. Andrew Pickering, pp. 343-368. Chicago: Chicago University Press.

Carlile, Paul R., Davide Nicolini, Ann Langley, and Haridimos Tsoukas, eds. 2013. How Matter Matters: Objects, Artifacts, and Materiality in Organization Studies. Oxford: Oxford University Press.

Collins, Harry M., and Steven Yearley. 1992. "Epistemological Chicken." In Science as Practice and Culture, ed. Andrew Pickering, pp. 301-326. Chicago: Chicago University Press.

Coole, Diana H., and Samantha Frost, eds. 2010. New Materialisms: Ontology, Agency, and Politics. Durham: Duke University Press.

Costall, Alan, and Ole Dreier, eds. 2006. Doing Things with Things: The Design and Use of Everyday Objects. Aldershot: Ashgate.

Dant, Tim. 2005. Materiality and Society. Maidenhead: Open University Press. 
de Léon, David. 2006. "The Cognitive Biographies of Things." In Doing Things with Things: The Design and Use of Everyday Objects, ed. Alan Costall and Ole Dreier, pp. 114-130. Aldershot: Ashgate.

Ellul, Jacques. 1964 [1954]. The Technological Society. New York: Knopf.

Gibson, James J. 1986 [1979]. The Ecological Approach to Visual Perception. Hillsdale: Lawrence Erlbaum Associates.

Grundmann, Reiner, and Nico Stehr. 2000. "Social Science and the Absence of Nature: Uncertainty and the Reality of Extremes." Social Science Information 39(1): 155-179.

Harper, Douglas. 1987. Working Knowledge: Skill and Community in a Small Shop. Chicago: University of Chicago Press.

Heidegger, Martin. 1977 [1962]. The Question Concerning Technology and Other Essays. New York: Garland.

Henare, Amira, Martin Holbraad, and Sari Wastell, eds. 2007. Thinking Through Things: Theorising Artefacts Ethnographically. London: Routledge.

Hicks, Dan. 2010. "The Material-Cultural Turn: Event and Effect." In The Oxford Handbook of Material Culture Studies, ed. Dan Hicks and Mary C. Beaudry, pp. 25-98. Oxford: Oxford University Press.

Hutchins, Edwin. 1995. Cognition in the Wild. Cambridge, MA: MIT Press.

Knappett, Carl, and Lambros Malafouris, eds. 2008. Material Agency: Towards a Non-Anthropocentric Approach. New York: Springer.

Latour, Bruno. 1988. "Mixing Humans and Nonhumans Together: The Sociology of a Door-Closer." Social Problems 35(3): 298-310.

Latour, Bruno. 2002. "Morality and Technology: The End of the Means." Theory, Culture \& Society 19(5/6): 247-260.

Law, John, and Annemarie Mol. 1995. "Notes on Materiality and Sociality." The Sociological Review 43(2): 274-294.

Lemke, Thomas. 2015. "New Materialisms: Foucault and the 'Government of Things'." Theory, Culture \& Society 32(4): 3-25.

Meskell, Lynn, ed. 2005. Archaeologies of Materiality. Malden: Blackwell.

Miller, Daniel, ed. 1998. Material Cultures: Why Some Things Matter. Chicago: University of Chicago Press.

Miller, Daniel, ed. 2005. Materiality. Durham: Duke University Press.

Miller, Daniel. 2008. The Comfort of Things. Cambridge: Polity Press.

Miller, Daniel. 2010. Stuff. Cambridge: Polity Press.

Molotch, Harvey L. 2003. Where Stuff Comes From: How Toasters, Toilets, Cars, Computers, and Many Others Things Come to Be As They Are. New York: Routledge.

Norman, Donald A. 2002 [1988]. The Design of Everyday Things. Cambridge, MA: MIT Press.

Orr, Julian E. 1996. Talking About Machines: An Ethnography of a Modern Job. Ithaca, NY: ILR Press.

Pickering, Andrew. 1993. "The Mangle of Practice: Agency and Emergence in the Sociology of Science." American Journal of Sociology 99(3): 559-589.

Pickering, Andrew. 1995. The Mangle of Practice: Time, Agency, and Science. Chicago: University of Chicago Press.

Pinch, Trevor J., and Richard Swedberg, eds. 2008. Living in a Material World: Economic Sociology Meets Science and Technology Studies. Cambridge, MA: MIT Press. 
Reckwitz, Andreas. 2002. "The Status of the 'Material' in Theories of Culture: From 'Social Structure' to 'Artefacts'." Journal for the Theory of Social Behaviour 32(2): 195-217.

Rheinberger, Hans-Jörg. 1997. Toward a History of Epistemic Things: Synthesizing Proteins in the Test Tube. Stanford, CA: Stanford University Press.

Sayes, Edwin. 2014. "Actor-Network Theory and Methodology. Just What Does it Mean to Say that Nonhumans have Agency?" Social Studies of Science 44(1): 134-149. Turkle, Sherry, ed. 2008. Falling for Science: Objects in Mind. Cambridge: MIT Press. Verbeek, Peter-Paul. 2005. What Things Do: Philosophical Reflections on Technology, Agency, and Design. University Park: Pennsylvania State University Press. 